\title{
The Content of Fluoride, Calcium and Magnesium in the Hair of Young Men of the Bantu Language Group from Tanzania Versus Social Conditioning
}

\author{
Ewa Rębacz-Maron • Irena Baranowska-Bosiacka • \\ Izabela Gutowska • Natalia Krzywania • \\ Dariusz Chlubek
}

Received: 9 September 2013 / Accepted: 3 October 2013 /Published online: 14 November 2013

(C) The Author(s) 2013. This article is published with open access at Springerlink.com

\begin{abstract}
The present study aimed at analysing the content of fluorine $(\mathrm{F})$, calcium $(\mathrm{Ca})$ and magnesium $(\mathrm{Mg})$ in the hair of young male students $(n=52)$ of a secondary school in Mafinga in Tanzania (Africa) who participated in anthropological examinations. $\mathrm{Ca}$ and $\mathrm{Mg}$ concentrations were determined using atomic absorption spectrophotometer while $\mathrm{F}$ levels using a potentiometric method. $\mathrm{F}$ in the hair of boys from older group ( $\geq 16$ years old; $n=24$ ) was significantly higher than in the younger group $(<16$ years old; $n=28)$ versus $\mathrm{Ca}$ and $\mathrm{Mg}$ levels. High carbohydrate diet was predominant - mainly based on corn or bean and meat served once a week, with few fruit and raw vegetables. Collective catering in the dormitory reflected habits and culinary preferences at home. The lack of balanced diet, with majority of the nutritional energy supplied by easily accessible and cheap carbohydrates, was reflected in dietary deficiencies, characterised, among others, by visible skin conditions and tooth decay.
\end{abstract}

Keywords Fluoride $\cdot$ Calcium $\cdot$ Magnesium $\cdot$ Hair $\cdot$ Bantu

E. Rębacz-Maron $(\square)$

Department of Anthropology, University of Szczecin, Str. Waska 13,

71-415 Szczecin, Poland

e-mail: rebae@univ.szczecin.pl

I. Baranowska-Bosiacka $\cdot$ N. Krzywania $\cdot$ D. Chlubek

Department of Biochemistry, Pomeranian Medical University,

Powstańców Wlkp. av. 72, 70-111 Szczecin, Poland

I. Gutowska

Department of Biochemistry and Human Nutrition, Pomeranian

Medical University, Broniewskiego Str. 24, 71-460 Szczecin, Poland

\section{Introduction}

The analysis of the content of chemical elements in hair is an important tool in toxicological and ecological examinations and recently is the most studied biomarkers [1-4]. Due to simplicity and non-invasive character of sampling, it is an alternative for blood, urine and biopsy material analyses. The latter method is most likely the most reliable one, but in some communities, it evokes doubts of ethical nature and cannot be used commonly. This is particularly important when examining hardly accessible environments, with black populations living in their indigenous environments being treated like such ones. The content of chemical elements in hair is determined, among others, by diet, sex, age, race and individual organism's requirement for them as well as by socio-economic conditions [5-8]. Also, the content of chemical elements in drinking water, geographical location and environmental pollution connected with civilisational progress and population are of importance [6]. Chemical elements are being permanently incorporated into hair structure over the whole time of their growth and the same they characterise the mineral state of organism during the last few or several months. The concentration of mineral elements in hair correlates with their content in the whole human organism, thus their content in hair can be a good indicator of organism saturation with them [9]. In literature, papers concerning the content of chemical elements in organisms of black populations living in their indigenous environments are not numerous. In particular, there are no reports referring to hardly accessible environments, like the Tanzania's region examined by us. In many countries of Africa, there is no infrastructure for collecting statistical information or social consent for performing regular biosocial examinations. Current data and information referring to biological development, body constitution, nutrition and family structure 
could be a valuable source of information on transformations in African communities. The present study aimed at analysing the content of chemical elements fluoride $(\mathrm{F})$, calcium $(\mathrm{Ca})$ and magnesium $(\mathrm{Mg})$ in easily available biological media like hair.

\section{Material and Methods}

\section{Examinated Group}

Material for analysis of the concentration of F, $\mathrm{Ca}$ and $\mathrm{Mg}$ in hair collected in October 2005 and March 2006 came from young male $(n=52)$ students of secondary school in Mafinga, Iringa District in Tanzania. The hair probes were collected from the nape of the neck. The students participated in anthropological examinations carried out in October 2005, during which information was collected, among others, on their tribal descent and permanent residence. Due to the broad age range of subjects (12.93-18.75), they were separated into two age groups: a younger group $<16$ years old $(n=28)$ and an older group $\geq 16$ years old $(n=24)$. They had been staying in the place where examination was carried out for a period of a few or several months only. For the study period, they had been accommodated in a dormitory and took advantage of day-long sustenance.

\section{Analysis of the Element Contents in Hair}

Ca and Mg Determination Hair samples were obtained from students who did not have coloured or treated hair. Initially, the hair was cleaned out in ultrasonic bath for $1 \mathrm{~h}$ and next washed twice using acetone and dried overnight in laminar flow hood at $25^{\circ} \mathrm{C}$. Thereafter, probes were digested using mixture of $1 \mathrm{~mL}$ of $65 \% \mathrm{HNO}_{3}$ and $1 \mathrm{~mL}$ of $70 \% \mathrm{HClO}_{4}$, dried once again $\left(48 \mathrm{~h} / 25^{\circ} \mathrm{C}\right)$, mineralized $(30 \mathrm{~min} / \mathrm{BM}-1 \mathrm{~S} / \mathrm{II}$ microwave mineraliser, Plazmotronika, Wrocław, Poland) and dried under nitrogen. For calcium and magnesium determination, hair sample was dissolved in $1 \mathrm{ml}$ of concentrated $65 \%$ $\mathrm{HNO}_{3}$. From this basic solution, $10 \mu \mathrm{l}$ was taken to plastic test tubes and added $5 \mathrm{ml} \mathrm{H}_{2} \mathrm{O}$. Calcium and magnesium concentrations were determined using atomic absorption spectrophotometer (AAS) 9100X PHILIPS. The apparatus was calibrated using standard solutions. The calibration curve was drawn automatically by the computer coupled with the apparatus. The determinations were performed in an air-acetylene flame for the relevant lamps at the following wavelengths: $\mathrm{Ca}-$ $422.7 \mathrm{~nm}$ (with an added $0.5 \%$ lanthanum buffer solution) and $\mathrm{Mg}-285.2 \mathrm{~nm}$ (with an added $0.1 \%$ lanthanum or strontium as a buffer solution).

$F$ Determination For fluoride determination hair sample was dissolved in $1 \mathrm{ml}$ of $2 \mathrm{M}$ perchloric acid $\left(1 \mathrm{~h} / 95^{\circ} \mathrm{C}\right)$. From the resultant solution, $0.5 \mathrm{ml}$ was poured into polyethylene cups, to which $2.5 \mathrm{ml}$ of TISAB II (total ionic strength adjustment buffer) buffer solution and $2 \mathrm{ml} 1 \mathrm{M}$ sodium citrate were added. Fluoride contents were determined with a potentiometric method, using Thermo Orion ion-selective electrode (The Thermo Scientific, USA). The electrode was calibrated using standard solutions.

\section{Statistical Analysis}

The results were analysed statistically using the software package Statistica 6.1. Arithmetical mean and the standard deviation (SD) were found for each of the studied parameters. The distribution of results for individual variables was obtained with the Shapiro-Wilk $W$ test. As most of the distributions deviated from the normal Gaussian distribution, nonparametric tests were used for further analyses. Correlations between the changes of the parameters were examined with the Spearman's rank correlation coefficient. To assess the differences between the studied groups, the non-parametric Mann-Whitney test was used. The level of significance was $p \leq 0.05$.

\section{Results}

Mean contents of the analysed chemical elements in the hair of Bantu language group males are presented in Figs. 1, 2 and 3.

Fluoride content in the hair of boys from older group was $49 \%$ higher than in younger group, and the difference was statistically significant $(p<0.006)$ (Fig. 1).

On the other hand, higher $\mathrm{Ca}$ content (about $4 \%$ ) was found in the hair samples from the younger group, but there were no statistically significant differences (Fig. 2).

Similar results were noted for $\mathrm{Mg}$ content in the hair samples. Despite the higher magnesium content in the hair of a younger group of around $14 \%$ compared with the older one, the difference was not statistically significant (Fig. 3).

Spearman's test showed the occurrence of dependence between the concentrations of the examined elements in the hair. The content of fluoride was negatively correlated with the concentration of Ca in older group $\left(R_{\mathrm{s}}=-0.36, p=0.002\right)$. Additional age positively correlated with the body mass index $\left(\mathrm{BMI}=\mathrm{kg} / \mathrm{m}^{2}\right)$ in both examined groups $\left(R_{\mathrm{s}}=0.44, p=0.001\right.$ for younger group and $R_{\mathrm{s}}=0.44, p=0.004$ for older group) and the highly negative with $\mathrm{Mg}$ content in samples from older group $\left(R_{\mathrm{s}}=-0.39, p=0.01\right)$.

BMI was calculated for the subjects showing that out of 50 men participating in the study, $19 \%$ was characterised by mediocre nutrition $(\mathrm{BMI} \leq 18.49)$. No statistically significant correlations were found between BMI and the analysed chemical elements. 


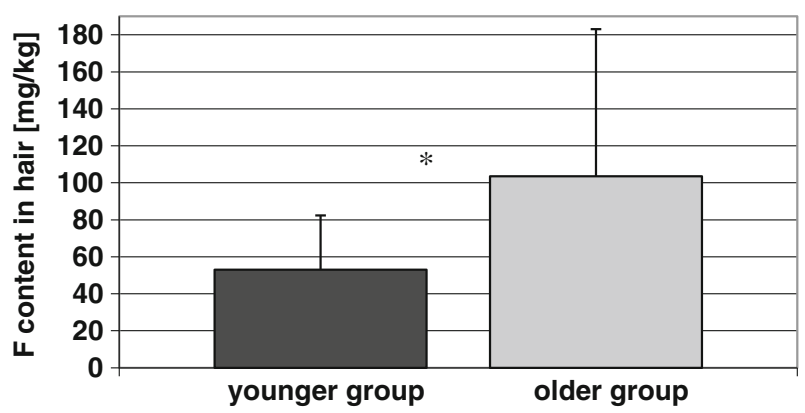

Fig. 1 The content of F [milligrams per kilogram dry mass] in the hair of Bantu language group males. ${ }^{*} p<0.006$ (significant difference between groups)

Socio-economic studies revealed a high percentage of parents with higher education $(59.6 \%$ of fathers and $42.3 \%$ of mothers); nevertheless, only $15.4 \%$ of subjects confirmed that they are satisfied with financial status of their families (Table 1).

\section{Discussion}

Population studies in Africa are seriously hindered by socioeconomic factors and their consequences. The living conditions determine the supply of minerals in the daily diet, and the diet affects the mineral content in the body [6]. Intake of elements in humans can occur through food, water and incidental consumption of soils. Children may take up elements from the food they eat, ingestion of soil while playing or the water they drink [10]. An important role is played by sociocultural factors and living conditions which determine nutrition in terms of quantity and quality. The last two factors seem to be directly responsible for the levels of individual minerals in the human body [11].

Element concentrations in hair were correlated to food and soil in element-specific patterns [10]. Levels of elements in humans have conventionally been determined through the analysis of biological samples including hair [9] because of their

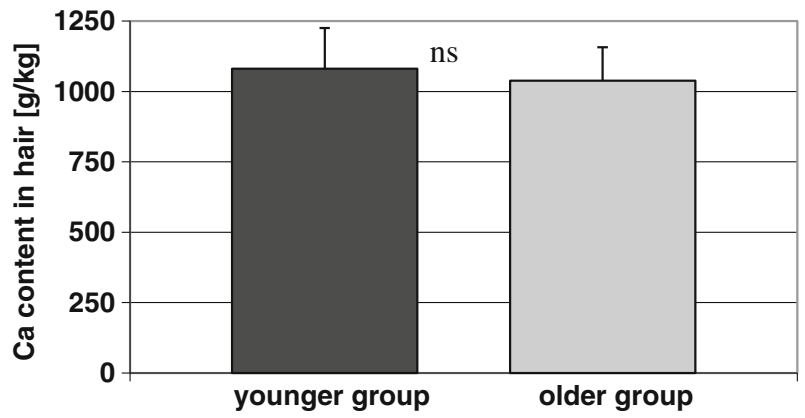

Fig. 2 The content of $\mathrm{Ca}$ [grams per kilogram dry mass] in the hair of Bantu language group males. $n s$ no significant difference between groups

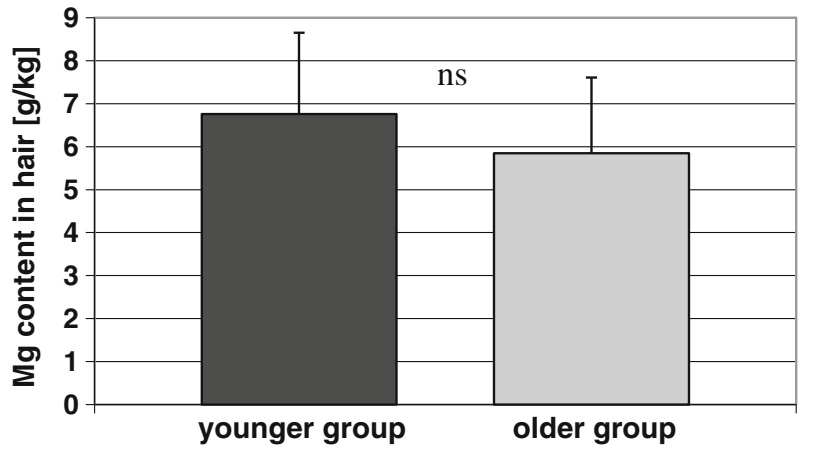

Fig. 3 The content of $\mathrm{Mg}$ [grams per kilogram dry mass] in the hair of Bantu language group males. $n s$ no significant difference between groups

easy to store and because the concentration in hair has been established to reflect external exposure levels, and this material is a good indicator for certain elements to which people have been exposed during the previous 2 to 18 months [9].

Anthropological studies enabled to collect information related with student's nutrition, concerning not only the quality but also the quantity of consumed meals. With regard to the school where this study was conducted, a carbohydrate-rich diet was routine (based mainly on corn or bean, with meat served once a week). This diet included few fruits and raw vegetables. Collective catering in the dormitory reflected habits and culinary preferences, which young people observed at their home environment. However, the analysis focusing on the BMI index did not reveal significant differences between the studied groups. Despite reporting $19 \%$ cases of malnutrition, many alumni "compensated" their body mass deficits after living in the facility for several months. Nonetheless, lack of a balanced diet, and above all, the fact that majority of the supplied nutritional energy was covered by easily accessible and cheap carbohydrates $(59.4 \%$ of the total supplied nutritional energy), and the fact that the diet contained no fruits and raw vegetables was reflected in dietary deficiencies, characterised among others by visible skin conditions and tooth decay.

It is common knowledge that in order to perform several physiological functions, human organism simultaneously requires large amounts of macroelements, such as magnesium and calcium, and small concentrations of trace elements, for example fluorine [12]. Based on the analysis related with the content of trace elements in hair conducted in both studied youth groups, the researchers did not observed drastic $\mathrm{Ca}$ and $\mathrm{Mg}$ deficiencies; nevertheless, the younger group revealed significantly lower $\mathrm{F}$ content in hair. It is difficult to comprehensively compare the obtained results with these obtained by other authors since studies on the content of elements in hair conducted among black populations (including people from Bantu language group) residing in home environment are a rarity, and what is more, noteworthy differentiation between studied environments makes it impossible to compare obtained results [13-15]. 
Table 1 Results of socioeconomic data for the whole materials and analysed age groups

$N A$ not available

\begin{tabular}{|c|c|c|c|c|c|c|}
\hline \multirow{2}{*}{$\begin{array}{l}\text { Socio-economic information } \\
\text { Question }\end{array}$} & \multicolumn{2}{|c|}{ Total $(n=52)$} & \multicolumn{2}{|c|}{ Age group $<16(n=28)$} & \multicolumn{2}{|c|}{ Age group $\geq 16(n=24$} \\
\hline & $n$ & $\%$ & $n$ & $\%$ & $n$ & $\%$ \\
\hline \multicolumn{7}{|c|}{ Self-estimation of material situation of family } \\
\hline Very good & 8 & 15.4 & 6 & 21.4 & 2 & 8.3 \\
\hline Rather good & 6 & 11.5 & 4 & 14.3 & 2 & 8.3 \\
\hline Average & 36 & 69.2 & 18 & 64.3 & 18 & 75.1 \\
\hline Rather bad & - & - & - & - & - & - \\
\hline Very bad & - & - & - & - & - & - \\
\hline NA & 2 & 3.9 & - & - & 2 & 8.3 \\
\hline \multicolumn{7}{|l|}{ Education status (mother) } \\
\hline None or primary & 3 & 5.8 & 1 & 3.6 & 2 & 8.3 \\
\hline Secondary school & 27 & 51.9 & 14 & 50.0 & 13 & 54.2 \\
\hline Higher & 22 & 42.3 & 13 & 46.4 & 9 & 37.5 \\
\hline NA & - & - & - & - & - & - \\
\hline \multicolumn{7}{|l|}{ Education status (father) } \\
\hline None or primary & - & - & - & - & - & - \\
\hline Secondary school & 20 & 38.5 & 6 & 21.4 & 14 & 58.3 \\
\hline Higher & 31 & 59.6 & 22 & 78.6 & 9 & 37.5 \\
\hline NA & 1 & 1.9 & - & - & 1 & 4.2 \\
\hline
\end{tabular}

Fluorine is enumerated among trace elements playing a crucial biological role [16]. It is present in all human tissues; however, its greatest concentration can be observed in bones and teeth $[17,18]$, where it constitutes a part of fluorapatites and hence stimulates both bone hardness and resilience $[17,19]$ as well as enamel solubility in teeth [19-21]. As far as our study is concerned, we observed a considerable difference in hair fluoride content between studied groups, which may reflect the concentration of this element in the organism. Since the physiological role played by fluorine is mainly related with bone tissue mineralization processes, its lowered content within the group of younger boys may cause disorders related with binding calcium, magnesium and phosphorus in bones, next to abnormalities relating teeth formation and enamel weakening $[18,20-22]$ in quickly developing organisms. These assumptions seem to confirm our observations associated with noticeably increased tooth decay among younger children. Increased magnesium content in hair reported in this group is yet another additional factor that may intensify the above-mentioned phenomena. Apart from the fact that magnesium participates in multiple important physiological functions [23], this element also activates enzymes taking part in synthesis, resorption and reconstruction of the bone tissue [23, 24]. However, its high concentration in hard tissues may stabilise the amorphic (immature) form of hydroxyapatite [25] and hence lead to rapid initiation and development of tooth decay and decreased bone hardness [25]. Calcium is an element, which plays two significant roles in human organism. When located in bones, it stands as a supporting structure of human skeleton, whereas when ionised in extracellular and intracellular fluid, it plays a notable biological role [26] and that is why its blood concentration is very precisely regulated and maintained on an appropriate level, at the expense of other tissues, for example bones [27]. The study did not reveal significant differences between the studied groups as far as calcium content in hair is concerned, which might probably result from the fact that in case of decreased supply of this element with food, its blood concentration was supplemented by mobilising the calcium stored in bones.

Despite quite high education, considering conditions of edification related with more expanded knowledge on health and the role played by macro- and microelements in proper development of the human organism, nutritional habits and in particular the economic situation constituted dominating factors influencing the diet selected at family home as well as in the place where boys enrolled in the study were taught, and all this posed considerable influence on concentrations of these elements in human organism. Population studies in Africa are seriously hindered by socio-economic factors and their consequences. The living conditions determine the supply of minerals in the daily diet, and the diet affects the mineral content in the body [6]. 
Conflict of Interest The authors declare that they have no conflicts of interest.

Open Access This article is distributed under the terms of the Creative Commons Attribution License which permits any use, distribution, and reproduction in any medium, provided the original author(s) and the source are credited.

\section{References}

1. Hambidge KM (1982) Hair analyses: worthless for vitamins, limited for minerale. Am J Clin Nutr 36:943-949

2. Marlowe M, Cossairt A, Welch K, Errera J (1984) Hair mineral content as a predictor of learning disabilities. J Learn Disabil 17(7):418-421

3. Klevay LM, Bistrian BR, Fleming CR, Neumann CG (1987) Hair analysis in clinical and experimental medicine. Am J Clin Nutr 46: 233-236

4. Batzevich VA (1995) Hair trace elements analyses in human ecology studies. Sci Total Environ 164:89-98

5. Creason JP, Hinners TA, Bumgarner JE, Pinkerton C (1975) Trace elements in hair, as related to exposure in metropolitan New York. Clin Chem 21:603-612

6. Taylor A (1986) Usefulness of measurements of trace elements in hair. Ann Clin Biochem 23:364-378

7. Nowak B, Chmielnicka J (2000) Relationship of lead and cadmium to essential elements in hair, teeth, and nails of environmentally exposed people. Ecotoxicol Environ Saf 46:265-274

8. Sukumar A (2002) Factors influencing levels of trace elements in human hair. Rev Environ Contam Toxicol 175:47-78

9. Rodrigues JL, Batista BL, Nunes JA, Passos CJS, Barbosa F Jr (2008) Evaluation of the use of human hair for biomonitoring the deficiency of essential and exposure to toxic elements. Sci Total Environ 405:370-376

10. Oyoo-Okoth E, Admiraal W, Osano O, Kraak MHS (2012) Element profiles in hair and nails of children reflect the uptake from food and the environment. Environ Toxicol Chem 31:1461-1469

11. Fraga CG, Oteiza PI, Keen CL (2005) Trace elements and human health. Mol Aspects Med 26:233-234

12. Apostoli P (2002) Element in environmental and occupational medicine. J Chromatogr B Analyt Technol Biomed Life Sci 998:63-97

13. Lewis, MP, Simons GF, Fennig CD (2013) Ethnologue: Languages of the World, Seventeenth edition. Dallas, Texas: SIL International. http://www.ethnologue.com/country/TZ of subordinate document. Accessed 10 Apr 2013
14. DeAntonio SM, Katz SA, Scheiner DM, Wood JD (1982) Anatomically-related variations in trace-metal concentrations in hair. Clin Chem 28:2411-2413

15. Othman I, Spyrou NM (1980) The abundance of some elements in hair and nail from the Machakos district of Kenya. Sci Total Environ $16: 267-278$

16. Dholam KP, Somani PP, Prabhu SD, Ambre SR (2013) Effectiveness of fluoride varnish application as cariostatic and desensitizing agent in irradiated head and neck cancer patients. Int J Dent 2013: 824982

17. Chachra D, Limeback H, Willett TL, Grynpas MD (2010) The longterm effects of water fluoridation on the human skeleton. J Dent Res 89:1219-1223

18. Gutowska I, Baranowska-Bosiacka I, Szynkowska A, Siwiec E, Szczuko M, Noceń I, Rębacz-Maron E, Chlubek D, Stachowska E (2012) Effect of supplementation with conjugated dienes of linoleic acid (CLA) on the content of fluoride, calcium and magnesium in the hard tissues and serum of mice. Fluoride 45:329-336

19. Fernandes MD, Yanai MM, Martins GM, Iano FG, Leite AL, Cestari TM, Taga R, Buzalaf MA, de Oliveira RC (2012) Effects of fluoride in bone repair: an evaluation of RANKL, OPG and TRAP expression. Odontology. doi:10.1007/s10266-012-0083-0

20. Gutowska I, Baranowska-Bosiacka I, Noceń I, Dudzińska W, Marchlewicz M, Wiszniewska B, Chlubek D (2011) Changes in the concentration of elements in the teeth of rats with type 1 diabetes, in the peak stage of the disease with absolute insulin deficit. Biol Trace Elemen Res 139:332-340

21. Aoba T (2004) Solubility properties of human tooth mineral and pathogenesis of dental caries. Oral Dis 10:249-257

22. Dos Santos AP, Nadanovsky P, de Oliveira BH (2012) A systematic review and meta-analysis of the effects of fluoride toothpastes on the prevention of dental caries in the primary dentition of preschool children. Community Dent Oral Epidemiol. doi:10.1111/j.16000528.2012.00708.x

23. Swaminathan R (2003) Magnesium metabolism and its disorders. Clin Biochem Rev 24:47-66

24. Okano T (1996) Effects of essential trace elements on bone turnover - in relation to the osteoporosis. Nippon Rinsho 54:148-154

25. Fejerskov O, Kidd E (eds) (2006) Caries. Caries and clinical conduct. Medical Publisher Urban \& Partner, Wrocław

26. Morris HA, O'Loughlin PD, Anderson PH (2010) Experimental evidence for the effects of calcium and vitamin $\mathrm{D}$ on bone: a review. Nutrients 2:1026-1035

27. Shankar P, Khandare A (2012) Regulation and reversal of effects of fluoride on calcium homeostasis in rats. XXXth Conference of the International Society for Fluoride Research, Szczecin, Poland, September 5-8, p 55 